\title{
Perencanaan Instalasi Pengolahan Air Limbah Komunal Di Kelurahan Kedung Cowek Sebagai Upaya Revitalisasi Kawasan Pesisir Surabaya
}

\author{
Sabam Oraendo Ajakima dan Eddy S. Soedjono \\ Jurusan Teknik Lingkungan, Fakultas Teknik Sipil dan Perencanaan, Institut Teknologi Sepuluh \\ Nopember (ITS) \\ Jl. Arief Rahman Hakim, Surabaya 60111 Indonesia \\ e-mail: soedjono@enviro.its.ac.id
}

\begin{abstract}
Abstrak - Dalam mencapai universal acces tahun 2019, masih terdapat 15.958 rumah tangga yang tidak mendapatkan akses sanitasi yang layak di Kota Surabaya. Salah satu kelurahan yang disoroti adalah Kelurahan Kedung Cowek, sedangkan kelurahan ini merupakan kawasan pesisir yang akan menjadi objek pengembangan wisata Kota Surabaya. Kelurahan Kedung Cowek masih minim infrastruktur lingkungan yang memadai. Serta diketahui sebagian besar warga Kelurahan Kedung Cowek masih melakukan Buang Air Besar Sembarangan (BABS). Studi ini ditinjau dari aspek teknis dan finansial. Segi teknis meliputi perhitungan debit air limbah, diameter pipa, penanaman pipa, dimensi IPAL Komunal dan gambar teknik perencanaan, sedangkan aspek finansial meliputi investasi pembangunan, biaya operasi pemeliharaan, dan kesediaan masyarakat untuk turut berpartisipasi dalam program IPAL Komunal. Perencanaan IPAL Komunal diharapkan bisa menjadi salah satu upaya revitalisasi kawasan pesisir yang dilakukan oleh Pemerintah Kota Surabaya. Hasil dari perencanaan ini berupa Sistem Penyaluran Air Limbah (SPAL) dan IPAL Komunal berupa Anaerobic Baffled Reactor (ABR) dan Aerobic Filter (AF). Area pelayanan mencakup RW 02 dan RW 03 dengan persen pelayanan $80 \%$ di tahun 2017, 85\% di tahun 2026, dan 90\% di tahun 2036. Keterlibatan masyarakat sangat dianjurkan untuk menjaga kesinambungan pengoperasian sarana kesehatan lingkungan. Adanya pembentukan UPT dan kader lingkungan akan memudahkan kegiatan pengoperasian dan perawatan SPAL \& IPAL Komunal Kelurahan Kedung Cowek sedangkan besarnya biaya retribusi swadaya masyarakat sebesar Rp 10.000,00/KK.bulan
\end{abstract}

Kata Kunci-ABR dan AF, Ipal Komunal, kader lingkungan, pesisir, revitalisasi.

\section{PENDAHULUAN}

$\mathrm{D}$ aerah-daerah kumuh perkotaan, sanitasi yang tidak memadai, kepadatan penduduk yang berlebihan, serta air yang terkontaminasi secara sekaligus dapat menciptakan kondisi yang tidak sehat. Penyakit yang paling sering didapati pada daerah kumuh biasanya berupa disentri, kolera, tipus, diare, hepatitis, demam berdarah, dan berbagai macam penyakit lainnya. Rendahnya pengetahuan dan pendidikan warga di permukiman kumuh akan sanitasi juga menjadi kendala dalam mengatasi masalah tersebut. Sanitasi dan perilaku kebersihan yang buruk berUpaya terhadap 88 persen kematian masyarakat di Indonesia. Kondisi ini selanjutnya menimbulkan implikasi serius terhadap kualitas sumber daya manusia dan kemampuan produktif suatu bangsa di masa yang akan datang. Angka penderita penyakit diare lebih tinggi sebesar 66 persen pada warga yang melakukan buang air besar di sungai atau selokan dibandingkan pada rumah tangga dengan fasilitas toilet pribadi dan septic tank [1].

Kelurahan Kedung Cowek, merupakan salah satu kawasan kumuh di Kecamatan Kenjeran, Surabaya. Kelurahan Kedung Cowek memiliki fasilitas baik fisik, ekonomi maupun infrastruktur yang kurang memadai. Isu lingkungan seperti kondisi sanitasi yang buruk pada kawasan perumahan dan permukiman di Kelurahan Kedung Cowek umumnya muncul karena dipicu tingkat urbanisasi yang tinggi, rendahnya pendidikan, pemanfaatan sumber daya dan teknologi yang kurang terkendali, kelangkaan prasarana dan sarana, serta ketidakmampuan memelihara dan memperbaiki lingkungan permukiman.

Tahun 2015 merupakan tahun awal dari upaya Pemerintah Kota Surabaya dalam menata kawasan pesisir di sepanjang Pantai Kenjeran. Upaya revitalisasi kawasan pesisir bertujuan untuk mengoptimalkan potensi wisata, dan perikanan tanpa melupakan kualitas lingkungan di daerah terebut. Upaya Pemkot Surabaya dilakukan dengan cara meningkatkan berbagai prasarana dan sarana pendukung, seperti ruang terbuka hijau, lapangan olah raga, tempat usaha perdagangan terbatas, fasilitas sosial atau fasilitas umum, peningkatan pelayanan air bersih, dan pengelolaan limbah domestik maupun hasil kegiatan perikanan [1].

Keterlibatan antara Pemerintah Kota Surabaya dengan masyarakat merupakan kunci utama agar upaya revitalisasi kawasan pesisir bisa tercapai. Melalui revitalisasi tersebut, diharapkan Surabaya mampu membenahi dan memperkecil persentase kawasan kumuh. Selain itu juga bisa menjaga kualitas lingkungan dan meningkatkan pendapatan daerah dengan potensi wisata dan pemberdayaan masyarakat di kawasan pesisir.

\section{METODE PERENCANAAN}

Tahapan dalam metode perencanaan adalah sebagai berikut: 


\section{A. Ide awal.}

Perencanaan pada studi ini diambil dari kesenjangan antara kondisi eksisting dengan kondisi ideal yang direncanakan oleh pemerintah. Kelurahan Kedung Cowek memiliki pemukiman nelayan yang terdapat pada pesisir pantai Surabaya. Awal Tahun 2015 merupakan awal Pemerintah Kota Surabaya dalam membenahi sepanjang pesisir pantai. Kegiatan pembenahan ini bisa dibilang sebagai upaya revitalisasi potensi kawasan pesisir pantai agar menjadikannya sebagai salah satu wisata unggulan di Surabaya. Proses revitalisasi melingkupi beberapa aspek, salah satunya adalah infrastruktur lingkungan. sebanyak 153 KK di Kelurahan Kedung Cowek masih memiliki akses pengolahan air limbah rumah tangga yang kurang layak, kondisi ini tentu sangat mengkhawatirkan sebagai kawasan wisata. Berdasarkan hal tersebut, maka muncul ide untuk merencanakan IPAL Komunal di Kedung Cowek. IPAL ini diharapkan bisa menjadi salah satu Upaya dari program revitalisasi pesisir pantai Kota Surabaya.

\section{B. Studi literatur.}

Studi literatur merupakan tahapan pengumpulan literatur dari berbagai buku, jurnal, dan refrensi lain yang bertujuan untuk mendapatkan teori acuan dalam melaksanakan perencanaan dan mampu menyelesaikan masalah dengan baik. Studi pustaka diperlukan sebagai landasan teori dalam melaksanakan perencanaan ini. Studi pustaka dilakukan bisa berasal dari beberapa macam sumber seperti jurnal nasional maupun internasional, textbook atau handbook yang bersangkutan mengenai pengolahan air limbah rumah tangga, artikel, dan perturan atau kebijakan pemerintah yang sedang berlaku.

\section{Pengumpulan data.}

Pengumpulan data merupakan tahapan observasi data yang dilakukan secara langsung oleh pelaksana studi (data primer) dan juga data yang tidak secara langsung (data sekunder). Data yang didapat haruslah data yang representatif dengan permasalahan yang akan dikaji. Sistematika pengumpulan data bisa dilihat pada Gambar 1.

\section{1) Data Primer}

Data primer merupakan data yang langsung diperoleh dari kondisi objek perencanaan. Metode yang digunakan dalam pengumpulan data primer adalah pengamatan atau survei langsung kondisi pengolahan air limbah rumah tangga di daerah perencanaan untuk mengetahui perilaku Buang Air Besar di Kelurahan Kedung Cowek serta mendapatkan luas dan kontur lahan perencanaan. Metode yang kedua adalah wawancara dengan angket. Kegiatan wawancara dilakukan agar mendapat informasi lebih dalam mengenai kondisi pengolahan air limbah rumah tangga di lokasi perencanaan melalui tokoh masyarakat seperti ketua RT, Ketua RW, dan juga Kepala Lurah ataupun Kepala Camat mengenai informasi revitalisasi pesisir pantai Kota Surabaya.

\section{- Pengamatan atau survei lapangan}

Pengamatan dan survei lapangan dilakuka di daerah perencanaan yaitu Kelurahan Kedung Cowek, Kecamatan
Bulak, Kota Surabaya. Hal yang diamati adalah kepemilikan jamban keluarga, kondisi MCK bersama, saluran pembuangan, atau fasilitas sanitasi lain yang digunakan sehari-hari. Survei lapangan juga bertujuan untuk mengetahui luas dan kontur lahan perencanaan. Pengukuran ini berguna untuk perancangan sistem penyaluran dari rumah-rumah atau dari MCK bersama menuju IPAL Komunal. Hasil dari pengamatan dan survei lapangan berupa foto-foto dokumentasi yang digunakan sebagaidata pendukung menggambarkan kondisi aktual Kelurahan Kedung Cowek.

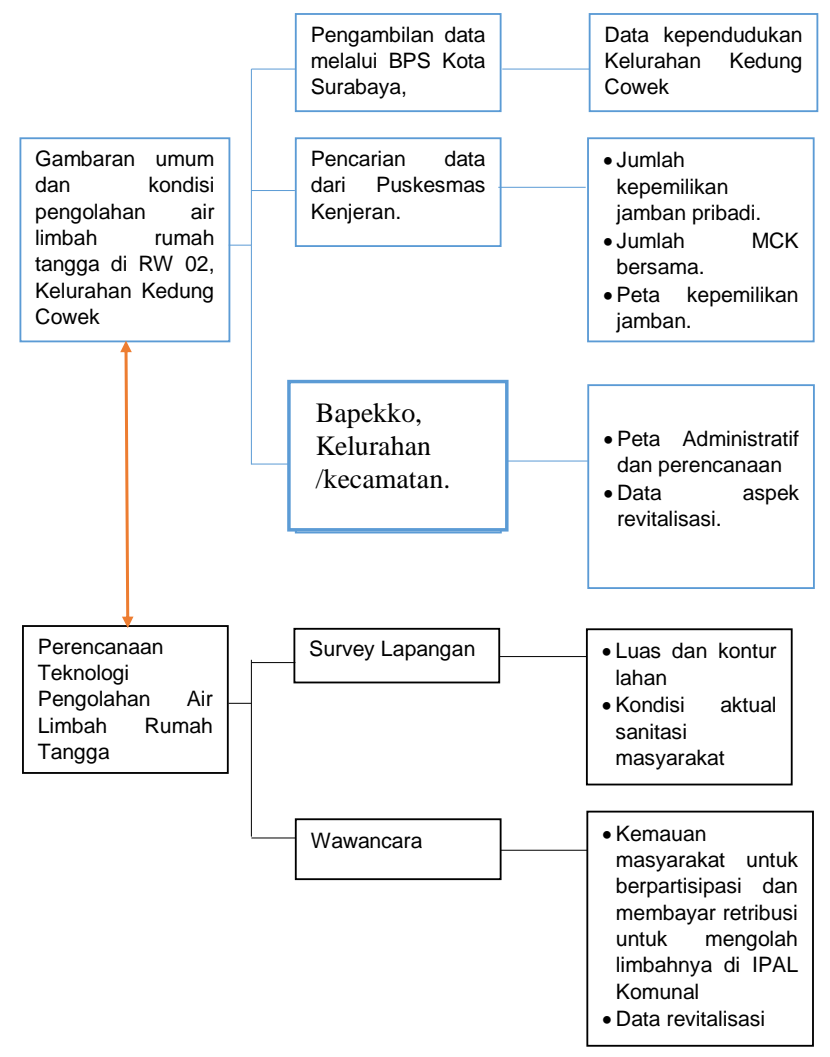

Gambar 1. Diagram Pengumpulan Data

\section{- Wawancara}

Kegiatan wawancara akan dilakukan kepada Ketua RT, Ketua RW, Lurah, Camat, Sanitarian Puskesmas Kenjeran, serta beberapa tokoh/masyarakat yang tinggal di daerah perencanaan. Penentuan responden untuk diwawancara adalah berdasarkan wewenang dan perannya di masyarakat. Responden ketua RT/RW dipilih karena keterkaitannya langsung dengan kehidupan sehari-hari warga sekitar, responden Lurah dan Camat dipilih karena dianggap paling mengerti kondisi masyarakatnya secara birokrasi, Sanitarian Puksesmas Kenjeran dipilih karena mengetahui perilaku Buang Air Besar masyarakat daerah setempat.

\section{2) Data Sekunder}

Data sekunder merupakan data yang diperoleh dengan tujuan untuk mendukung data primer yang telah ada. Data sekunder diperoleh dari instansi pemerintah maupun kelembagaan antara lain: BAPEKKO Surabaya, Bapan Pusat 
Statistik Kota Surabaya, Dinas Kesehatan Kota Surabaya, Badan Lingkungan Hidup Surabaya, Puskesmas Kenjeran, Kelurahan Kedung Cowek dan Kecamatan Bulak. Data sekunder juga bisa didapatkan dari pencarian melalui internet. Data sekunder yang dibutuhkan dalam perencanaan terdapat pada Tabel 1.

Tabel 1.

Kebutuhan Data Sekunder

\begin{tabular}{ccc}
\hline \hline Instansi & Data/dokumen & Kegunaan \\
\hline & Memorandum & \\
Program Sektor & Sanitasi Kota dan \\
Revitalisasi & Kebijakan, \\
Pesisir 2012-206 & sasaran \\
& $\&$ 2015-2020 & \\
Dinas Kesehatan & Profil STBM & Kondisi Eksisting \\
& & Capaian STBM \\
& & Data pendukung \\
Badan Pusat Statistik & Kecamatan Dalam & analisis \\
& Angka & kependudukan, \\
& & geografis, dll. \\
& & kondisi eksisting \\
Puskesmas & Profil sanitasi & sanitasi \\
& & kecamatan Bulak \\
& & \\
& & Data pendukung \\
Kecamatan/keluraha & Program & sebagai antara \\
& Revitalisasi & IPAL dan Upaya \\
& Pesisir & untuk revitalisasi \\
& & \\
& &
\end{tabular}

a. Analisis dan pembahasan

\section{- Teknis}

Analisis dilakukan setelah data primer dan data sekunder didapatkan. Data primer dan data sekunder yang telah diperooleh merupakan informasi penting untuk merencanakan teknologi pengolahan air limbah rumah tangga yang sesuai dengan kondisi masyarakat di Kelurahan Kedung Cowek. Alternatif teknologi bisa berupa Anaerobic Baffle Rector atau Anarobic Biofilter. Kedua pilihan teknologi akan dianalisis sesuai dengan debit dan karakteristik air limbah rumah tangga yang akan diolah serta hubungannya dengan efisiensi pengolahan berdasarkan studi literatur. Target pelayanan adalah seluruh untuk seluruh warga Kelurahan Kedung Cowek. Rincian pelayanan adalah: semua warga yang belum memiliki jamban pribadi, warga yang sudah memiliki jamban pribadi, dan MCK bersama. Setelah teknologi pengolahan air libah rumah tangga dipilih, kemudian akan dibuat gambaran awal tata letak IPAL Komunal beserta profil hidrolis dengan kondisi lahan di daerah perencanaan, lalu dibuat Detail Engineering Design sesuai dengan alternatif teknologi yang telah dipilih.

\section{- Finansial}

Analisis biaya meliputi pembiayaan pembangunan teknologi pengolahan air limbah rumah tangga sesuai dengan Bill of Quantity (BOQ) dan Rencana Anggaran Biaya (RAB), serta retribusi yang harus dibayarkan oleh masyarakat untuk pemelihaan IPAL Komunal yang telah dibangun.

b. Kesimpulan dan Saran

Berdasarkan hasil dan pembahasan akan ditarik sebuah kesimpulan yang menjawab tujuan dari perencanaan ini. Kesimpulan diharapkan bisa memberikan informasi maupun acuan dalam merencanaan IPAL Komunal di RW 02 Kelurahan Kedung Cowek, Kecamatan Bulak, Kota Surabaya. Saran diberikan untuk memberikan pembetulan pada perencanaan lebih lanjut sehingga perencanaan dapat lebih baik.

\section{HASIL DAN PEMBAHASAN}

\section{A. Upaya Revitalisasi Pesisir Surabaya}

Pembangunan kawasan pesisir pantai tak terlepas dari pembangunan pencitraan kawasan ini sebagai kebanggaan sebuah kota, yang merupakan kekuatan daya tarik kota tersebut sebagai kota dunia yang berkarakter dan berwibawa. Dipihak lain pembangunan karakter kawasan ini tak terlepas dari tujuan mengantisipasi persaingan kota bagi tujuan merebut pasar, melalui pembangunan dengan mengangkat kekuatan keunggulan citra sedemikian rupa sehingga membangkitkan daya tarik yang kompetitif bagi tujuan kepariwisataan, bisnis dan investasi. Untuk itu pula kota-kota dunia berlomba membangun citra yang kompetitif, dengan mengangkat semangat kota, yang pada umumnya dikaitkan dengan semangat masa lalu kota tersebut [2].

Untuk membiayai pembangunan tempat wisata Pantai Kenjeran tersebut, rencananya Pemerintah Kota Surabaya tidak mengeluarkan uang seperser pun untuk revitalisasi ini sebab ada investor yang mau mengerjakan revitalisasi tempat wisata tersebut. Namun Pemkot juga perlu untuk mempertimbangkan cara-cara lain untuk membiayai revitalisasi kedua tempat tersebut sehingga tidak hanya bergantung pada investor saja. Misalnya pembiayaan pembangunan bisa dengan cara kerjasama dengan warga setempat untuk membangun dan mengelola Kawasan Pantai Kenjeran Dengan melibatkan masyarakat sekitar. Masyarakat diharapkan turut andil dalam pemeliharaan Pantai Kenjeran sehingga dapat menjadi salah satu sumber potensi lapangan kerja bagi masyarakat dan penarik bagi wisatawan untuk menikmati Surabaya [3].

Suatu kegiatan dikatakan keberlanjutan, apabila kegiatan pembangunan secara ekonomis, ekologis dan sosial politik bersifat berkelanjutan. Berkelanjutan secara ekonomi berarti bahwa suatu kegiatan pembangunan harus dapat membuahkan pertumbuhan ekonomi, pemeliharaan capital (capital maintenance), dan penggunaan sumberdaya serta investasi secara efisien. Berkelanjutan secara ekologis mengandung arti, bahwa kegiatan dimaksud harus dapat mempertahankan integritas ekosistem, memelihara daya dukung lingkungan, dan konservasi sumber daya alam termasuk keanekaragaman hayati (biodiversity). Sementara itu, berkelanjutan secara sosial politik mensyaratkan bahwa suatu kegiatan pembangunan hendaknya dapat menciptakan pemerataan hasil pembangunan, mobilitas sosial, kohesi sosial, partisipasi masyarakat, 
pemberdayaan masyarakat (dekratisasi), identitas sosial, dan pengembangan kelembagaan [4].

Pengelolaan berbasis masyarakat dapat diartikan sebagai suatu sistem pengelolaan sumber daya alam di suatu tempat di mana masyarakat lokal ditempat tersebut terlibat secara aktif dalam proses pengelolaan sumber daya alam yang terkandung didalamnya. Di Indonesia pengelolaan sumberdaya berbasis masyarakat sebenarnya telah ditetapkan dalam Pasal 33 Undang-Undang Dasar 1945 yang menyebutkan bahwa bumi dan air dan kekayaan alam yang terkandung di dalamnya dikuasai oleh Negara dan dipergunakan sebesar-besarnya bagi kemakmuran rakyat. Ketentuan tersebut secara tegas menginginkan agar pelaksanaan penguasaan negara atas sumber daya alam khususnya sumber daya pesisir dan lautan diarahkan kepada tercapainya manfaat yang sebesar-besarnya bagi kemakmuran rakyat banyak, dan juga harus mampu mewujudkan keadilan dan pemerataan sekaligus memperbaiki kehidupan masyarakat pesisir serta memajukan desa-desa pantai.

Dari berbagai macam penjelasan di atas dapat dikatakan bahwa terdapat beberapa aspek penting dalam revitalisasi pesisir Surabaya antara lain adalah aspek wisata \& ekonomis, ekologis, dan politis. Dalam studi ini direncanakan sebuah sistem penyaluran air limbah (SPAL) dan instalasi pengolahan air limbah (IPAL) komunal di Kelurahan Kedung Cowek yang termasuk kawasan pesisir Surabaya. Perencanaan diharapkan bisa menjadi ide atau gagasan sebagai Upaya revitalisasi kawasan pesisir yang dicanangkan oleh Pemerintah Kota Surabaya khususnya pada aspek ekologis. Aspek ekologis yang dimaksud haruslah berkelanjutan dan berbasis masyarakat, dimana hal sinergis tersbut dapat menjaga dan meningkatkan kualitas lingkungan daerah pesisir dan peningkatan potensi pariwisata serta perekonomian masyarakat setempat.

\section{B. Proyeksi Penduduk Kelurahan Kedung Cowek}

Proyeksi penduduk dilakukan berdasarkan data kependudukan Kelurahan 4 tahun terakhir dengan memproyeksikan langsung berdasarkan jumlah KK/RT dimana RW II terdapat 4 RT yaitu RT 01, 02, 03, dan 04, sementara RW III terdapat 3 RT 01, 02, dan 03. Proyeksi menggunakan metode geometrik dengan nilai korelasi sebesar 0,9683. Proyeksi dilakukan sesuai dengan 3 tahap perencanaan yaitu tahun 2017, tahun 2026, dan tahun 2036. Adapun hasil proyeksi penduduk Kelurahan Kedung Cowek dapat dilihat pada Tabel 2.

Tabel 2

Jumlah Penduduk Kelurahan Kedung Cowek

\begin{tabular}{cccccc}
\hline \hline \multirow{2}{*}{ RW } & RT & \multicolumn{5}{c}{ Jumlah Penduduk } \\
& & 2014 & 2017 & 2026 & 2036 \\
& 1 & 1000 & 1038 & 1158 & 1309 \\
II & 2 & 550 & 571 & 637 & 720 \\
& 3 & 1150 & 1193 & 1332 & 1505 \\
& 4 & 1050 & 1090 & 1216 & 1374 \\
III & 1 & 748 & 776 & 867 & 979 \\
\hline \hline
\end{tabular}

\begin{tabular}{rcccc}
\hline \hline 2 & 440 & 457 & 510 & 576 \\
3 & 750 & 778 & 869 & 982 \\
$\Sigma$ penddk & 5688 & 5903 & 6589 & 7445 \\
$\mathrm{KK}$ & 1138 & 1181 & 1318 & 1489 \\
\hline \hline
\end{tabular}

\section{Hasil Survei Kuisioner}

\section{1) Profil Penduduk}

Menurut Tabel 3 menunjukkan bahwa sebagian besar masyarakat Kedung Cowek berprofesi sebagai nelayan sebanyak $41 \%$ dengan penghasilan $\mathrm{Rp} 40.000,00$ - Rp $150.000,00$ / bulan. Pekerjaan terbanyak kedua adalah pedagang sebanyak $25 \%$ dengan penghasilan rata-rata sebesar Rp 4.000.000,- / bulan. Kemudian pekerjaan terbanyak ketiga adalah pegawai swasta sebanyak $18 \%$ dengan penghasilan sebesar Rp 5.000.000,- / bulan. Setelah itu wiraswasta sebanyak 4\% dengan penghasilan rata-rata sebesar Rp 4.000.000,- / bulan. Setelah itu terdapat penduduk yang tidak bekerja sebesar $12 \%$.

Tabel 3

Komposisi Pekerjaan Warga Kd. Cowek

\begin{tabular}{ccc}
\hline Pekerjaan & Jumlah & $\%$ \\
\hline Belum Bekerja & 190 & 12 \\
Nelayan & 679 & 41 \\
Pedagang & 413 & 25 \\
Peg. Swasta & 305 & 18 \\
wiraswasta & 67 & 4 \\
\hline \hline
\end{tabular}

\section{2) Kepemilikan Tanki Septik}

Hasil wawancara menunjukkan, meskipun warga sudah memiliki WC dan tangki septik, namun kenyataannya warga masih melakukan kegiatan buang air besar di sembarangan. Kepemilikan WC dan perilaku buang air besar masyarakat bisa dilihat pada Tabel 3 dan Tabel 4.

Warga menyatakan bahwa kebiasaan buang air besar di laut merupakan sebuah tradisi atau budaya yang sudah dilakukan sejak dulu. Akses yang lebih mudah dijadikan alasan utama mengapa buang air besar dilakukan di laut. Selain karena sudah menjadi tradisi, masyarakat juga mengaku kurang adanya penyuluhan kesehatan mengenai sanitasi yang sehat terutama masalah buang air besar sembarangan dan dampaknya terhadap kesehatan pribadi, keluarga, dan lingkungan sekitar.

Penyuluhan sanitasi yang sehat diharapkan mampu memperkecil kontradiksi kepemilikan wc dan kebiasaan buang air besar warga Kedung Cowek. Kegiatan penyuluhan bisa menjadi salah satu cara mengubah mindset masyarakat agar mau hidup sehat dengan menggunakan fasilitas kesehatan yang telah dibangun.

Tabel 4

Kepemilikan WC dan Tangki Septik Pribadi

\begin{tabular}{ccc}
\hline \hline $\begin{array}{c}\text { Kepemilikan } \\
\text { WC }\end{array}$ & Jumlah sampel KK & $\%$ \\
\hline Sudah & 75 & 82 \\
Belum & 17 & 18 \\
Total & 92 & 100 \\
\hline \hline
\end{tabular}


Tabel 5

Kebiasaan BAB Warga Kedung Cowek

\begin{tabular}{ccc}
\hline \hline $\begin{array}{c}\text { Kebiasaan } \\
\text { BAB }\end{array}$ & $\begin{array}{c}\text { Jumlah } \\
\text { Sampel } \\
\text { KK }\end{array}$ & $\%$ \\
\hline Laut & 13 & 62 \\
MCK/WC & 8 & 38 \\
Total & 21 & 100 \\
\hline \hline
\end{tabular}

\section{3) Kesediaan Masyarakat}

Sebanyak 35\% warga yang kurang setuju dengan adanya Sistem IPAL Komunal di Kelurahan Kedung Cowek, sementara sisanya sebesar $65 \%$ setuju dan ingin berpartisipasi pada program IPAL Komunal. Adapun mayoritas warga yang tidak setuju merupakan sebagian besar dari warga RW I, oleh karena itu pelayanan pada perencanaan ini hanya mengikutsetakan warga pada RW II dan RW III Persentasi kesediaan masyarakat secara keseluruhan bisa dilihat pada Tabel 5 .

Tabel 6

Kesediaan Warga Berpartisipasi IPAL Komunal

\begin{tabular}{ccc}
\hline \hline Kesediaan & $\begin{array}{c}\text { Jumlah } \\
\text { Sampel } \\
\text { KK }\end{array}$ & $\%$ \\
\hline Ikut & 63 & 68 \\
Tidak & 29 & 32 \\
Total & 92 & 100 \\
\hline \hline
\end{tabular}

\section{Perencanaan SPAL dan IPAL Komunal}

Pada pembahasan kali ini, diambil 1 contoh jalur pipa yaitu jalur a6-a7 pada tahun 2017. Sistem penyaluran air limbah pada perencanaan ini menggunakan sistem konvensional dimana terdapat mandhole di setiap percabangan pipa dan menggunakan diameter sebesar 101,6 $\mathrm{mm}$ atau sebesar 4 inchi. Adapun kecepatan minimum (Vmin) yang didapat adalah sebesar 0,131 $\mathrm{m} /$ detik, dengan jenis pipa PVC dengan koefisien kekasaran sebesar 0,013. Layout jalur pipa a6-a7 bisa dilihat pada Gambar 3.

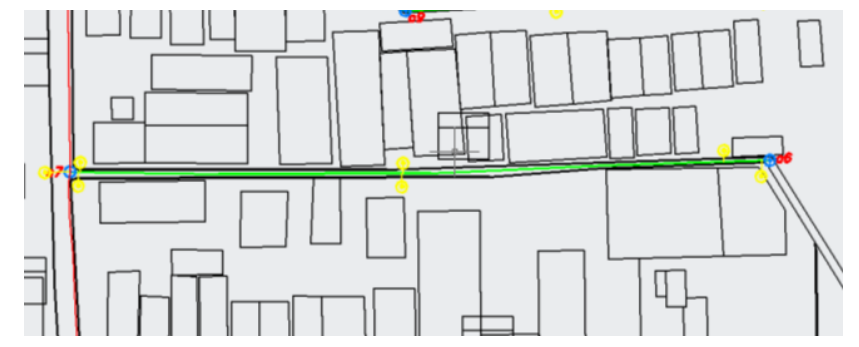

Gambar 3. Jalur Pipa a6-a7

Anaerobic Baffle Reactor (ABR) memiliki kriteria perencanaan sebagai berikut:

1) Kecepatan upflow (Vup) $=(0,7-1,6) \mathrm{m} / \mathrm{jam}$;

2) Organic Loading Rate $(\mathrm{OLR})=(0,85-6) \mathrm{kg} \mathrm{COD} / \mathrm{m}^{3} \cdot$ hari ;

3) Hydraulic Retention Time $(\mathrm{HRT})=(6-24)$ jam [5] ; Removal $\mathrm{COD}=(65-90) \% ;$ Removal $\mathrm{BOD}=(70-95) \%$; panjang bangunan $=(50-60) \%$ dari ketinggian bangunan

[6].

Sementara kriteria perencanaan untuk Anarobic Filter (AF) adalah sebagai berikut:

1) media filter $=(50-7-) \%$ dari ketinggian bangunan ;2) kecepatan upflow $=(0,6-2) \mathrm{m} / \mathrm{jam} ; 2)$ Hydraulic Retention Time $(\mathrm{HRT})=(4-10)$ jam ; 3) Organic Loading Rate $(\mathrm{OLR})=$ $(0,15-0,5) \mathrm{kg} \mathrm{BOF} / \mathrm{m}^{3}$.hari [6].

Dari kriteria di atas, didapatkan dimensi ABR dan AF yaitu: Luas lahan $=(25,8 \times 18,2) \mathrm{m}$, dengan ketinggian $=3,5 \mathrm{~m}$.

Unit ABR dan AF dipilih karena murah dalam operasional dan perawatan serta memiliki efisiensi yang cukup tinggi. Adapun denah serta potongan dari IPAL Komunal dapat dilihat pada Gambar 4, Gambar 5, dan Gambar 6.

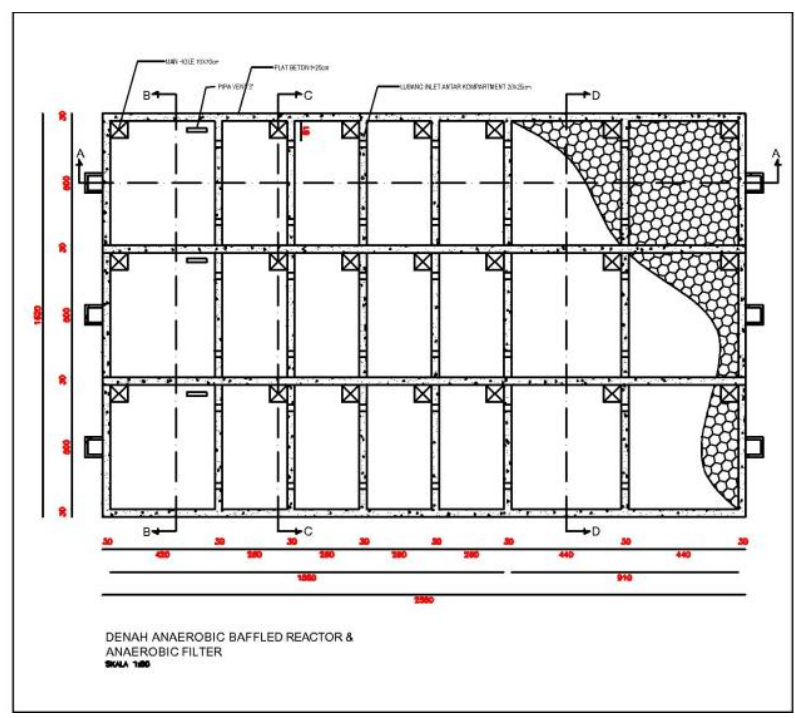

Gambar 4. Denah IPAL Komunal

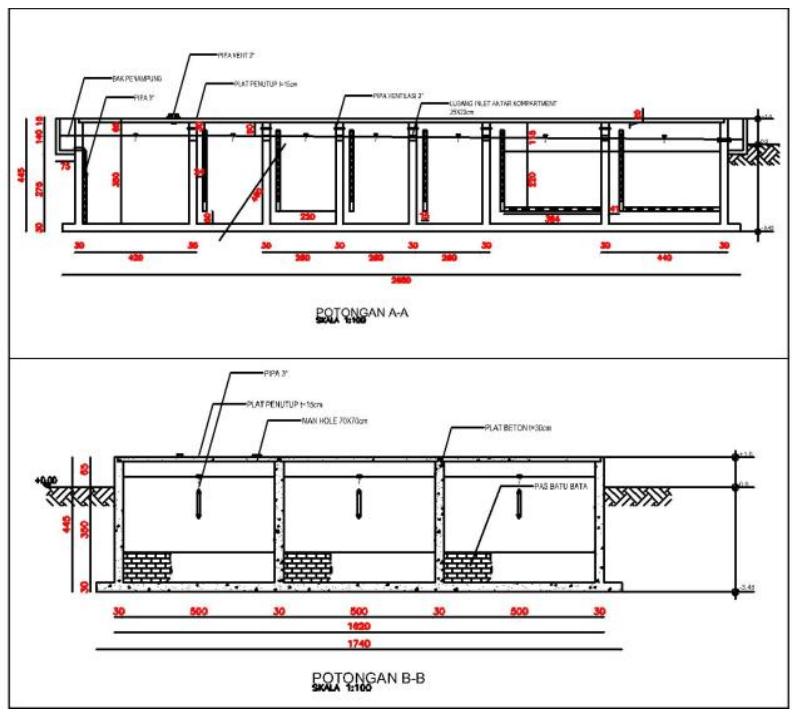

Gambar 5. Potongan AA dan BB IPAL Komunal 


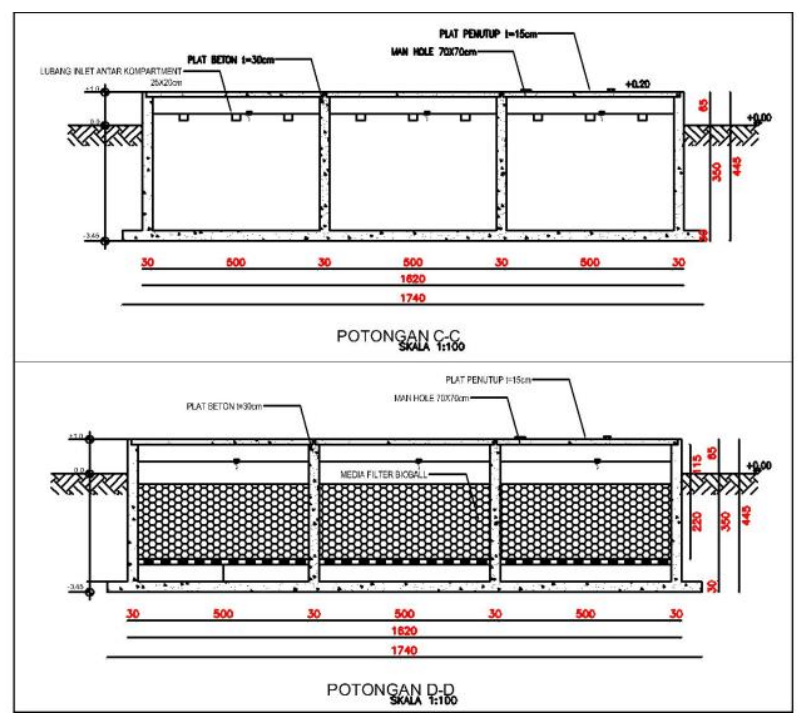

Gambar 6 otongan CC dan DD IPAL Komunal

\section{E. Bill of Quantity (BOQ) dan Rencana Anggaran Biaya $(R A B)$}

BOQ (Bill of Quantity) adalah perincian jumlah dari seluruh peralatan dan pekerjaan yang dibutuhkan di dalam perencanaan, sedangkan RAB (Rencana Anggaran Biaya) adalah biaya yang diperlukan dalam pengadaan peralatan dan biaya pembayaran tenaga kerja. Perhitungan rencana anggaran biaya pada perencanaan ini mengacu pada HSPK Kota Surabaya pada tahun 2015.

Pada perencanaan dilakukan 3 tahap pembangunan yaitu tahap pertama pada tahun 2017, tahap kedua pada tahun 2026, tahap ketiga pada tahun 2036. Pembobotan nilai HSPK pada tahun 2017 dianggap sama seperti nilai HSPK tahun 2015, sementara untuk HSPK tahun 2026 dan tahun 2036 dibobotkan berdasarkan proyeksi (menggunalan proyeksi metode geometrik) nilai inflasi sehingga biaya untuk ketiga tahap berbeda satu sama lain. Rata-rata nilai inflasi mata uang Rupiah (Rp) adalah sebesar 2,09 pada rata-rata tahun 20152016 [7]. Sehingga hasil proyeksi nilai inflasi terdapat pada Tabel 8.

Tabel 7

Proyeksi \% Inflasi Mata Uang Rupiah (Rp) Tahun 2026 dan Tahun 2036

\begin{tabular}{ccc}
\hline \hline No. & Tahun & Inflasi \\
\hline 1 & 2026 & $4,88 \%$ \\
2 & 2036 & $5,39 \%$ \\
\hline \hline
\end{tabular}

Dari perhitungan BOQ dan RAB yang sudah dilakukan maka didapatkan hasil rekapitulasi biaya investasi pembangunan SPAL dan IPAL Komunal Kelurahan Kedung Cowek seperti tertera pada Tabel 9.
Tabel 8

\begin{tabular}{ccc}
\multicolumn{3}{c}{ Rekapitulasi RAB SPAL dan IPAL Komunal Kelurahan Kedung Cowek } \\
\hline \hline No. & Jenis Pekerjaan & Biaya (Rp) \\
\hline 1 & Penggalian dan Penanaman & 441.146 .058 \\
& Pipa SPAL & 125.971 .383 \\
2 & Pembuatan Manhole & 267.524 .400 \\
3 & Pipa SPAL & 21.970 .000 \\
4 & Pompa & 635.563 .313 \\
5 & IPAL 2017 & 666.586 .802 \\
6 & IPAL 2026 & 669.834 .295 \\
7 & IPAL 2036 & $\mathbf{2 . 8 2 8 . 5 9 6 . 2 5 1}$ \\
\hline \hline
\end{tabular}

\section{F. Operasi Pemeliharaan IPAL oleh Masyarakat}

\section{1) Operasi dan Pemeliharaan}

Peran masyarakat yang aktif merupakan faktor penting dalam kesinambungan sarana yang ada. Elemen masyrakat yang aktif ini bisa dibentuk sebuah kelompok atau paguyuban semi organisasi yang berbasis lingkungan sebagai penanggung jawab atas sarana yang telah dibangun. Sekelompok masyarakat yang bersedia menjadi penanggung jawab dapat dinamakan sebagai Kader Lingkungan. Adapun tugas dari Kader Lingkungan antara lain:

a. Menyusun rencana kerja terkait pengoperasian dan pemeliharaan jaringan SPAL dan IPAL.

b. Kebijakan khusus mengenai pengelolaan sarana yang ada.

c. Turut serta mengajak masyarakat lain untuk berpartisipasi aktif menjaga dan memelihara SPAL dan IPAL Komunal.

d. Meningkatkan mutu pelayanan, mendengar keluhan masyarakat mengenai kendala teknis yang akan terjadi.

e. Melakukan kampanye kesehatan.

Selain menjalankan 5 kewajiban di atas, para kader lingkungan juga bertanggung jawab atas sosialisasi kepada masyarakat setempat terutama bagi warga yang belum berkeinginan untuk berpartisipasi dalam program IPAL Komunal. Secara garis besar kader lingkungan ini berkoordinasi langsung dengan para RT, RW, dan Lurah. Kader lingkungan tidak bergerak independen namun tetap dibawah regulasi yang berlaku sesuai norma dan nilai yang ada di masyarakat.

\section{Standard Operating Procedure (SOP)}

Standard Operating Procedure atau tata cara operasional ditujukan untuk para pengguna fasilitas dan juga operator yang bertugas pada IPAL Komunal. SOP (Standart Operating Procedure) ini bertujuan agar semua pihak yang terlibat samasama disiplin dan bertanggung jawab atas fasilitas yang ada karena fasilitas tersebut milik bersama dan untuk kepentingan bersama.

SOP untuk para pengguna:

a. Jangan membuang sampah atau limbah padat apapun ke dalam saluran air limbah baik melalui WC pribadi terlebih 
melalui saluranair limbah dan segala jenis bangunan pelengkapnya.

b. Jangan membuang bahan kimia ke dalam saluran air limbah. Zat kimia yang tidak diketahui bisa berpotensi mematikan bakteri pengolahan.

c. Gunakan sabun dan alat pembersih lain sewajarnya. Dilarang keras membuang pembersih porselein ke dalam saluran air limbah.

d. Ambil kotoran yang mengapung pada bak kontrol minimal sekali dalam sehari.

$\underline{\text { SOP untuk operator }}$

a. Periksa setiap bak kontrol yang ada pada semua saluran pipa air limbah minimal seminggu 2 kali.

b. Buang limbah padat yang mengapung pada bak kontrol

c. Jika tidak ada aliran pada bak kontrol maka hentikan MCK sementara, periksa mungkin ada pipa yang tersumbat atau rusak.

d. Jika ada air meluap dari bak kontrol, periksakan segera mungkin terjadi penyumbata, sogok dari bak kontrol satu ke bak kontrol lain.

e. Perawatan IPAL Komunal 1 kali minimal 6 bulan dengan cara mengambil kotoran yang mengapung pada kompartemen pertama sampai akhir

f. Lakukan pengurasan setidaknya 2 tahun sekali dengan menelfon instansi terkait jasa pengurasan IPAL.

Biaya retribusi perKK

$\begin{array}{ll}\text { Inspeksi pipa 8x/bulan } & =\operatorname{Rp~} 800.000,00 \\ \text { Pengurasan lumpur 2tahun sekali } & =\operatorname{Rp} 1.500 .000,00 \\ \text { Pemeriksaan sample effluen/bulan } & =\operatorname{Rp} 2.000 .000,00 \\ \text { Listrik dan pompa/bulan } & =\operatorname{Rp} 6.500 .000,00 \\ \text { Total } & =\operatorname{Rp} 10.800 .000 \\ \text { Iuran per warga } & =\operatorname{Rp~} 10.800,00 / 1138 \mathrm{KK} \\ & =\operatorname{Rp} 10.000 / \mathrm{KK}\end{array}$

\section{KesimpUlan}

Adapun kesimpulan pada perencanaan ini adalah sebagai berikut:

A. Sebanyak $82 \%$ masyarakat Kelurahan Kedung Cowek sudah memiliki jamban pribadi namun masih terdapat sebanyak 62\% masyarakat yang Buang Air Besar di Laut Kenjeran. Perilaku ini dilatarbelakangi oleh budaya dan kebiasaan masyarkat setempat. Perilaku buang air besar di laut banyak didapat pada keluarga nelayan. Adanya sosialisasi kesehatan dapat membantu warga nelayan sadar untuk tidak lagi buang air besar di laut. Kesadaran warga tersebut juga menjadi kunci agar sarana pengolahan air limbah yang dibangun tidak sia-sia.

B. Terdapat beberapa aspek yang menjadi tujuan revitalisasi yaitu, ekonomi-wisata, ekologis, dan politis. Perencanaan SPAL dan IPAL Komunal diharapkan menjadi salah satu Upaya revitalisasi khususnya dalam mewujudkan aspek ekologis yang berkelanjutan.
C. Sistem Penyaluran Air Limbah (SPAL) Kelurahan Kedung Cowek melayani RW 02 dan RW 03 atau 2/3 bagian dari total warga setempat. Bangunan pengolahan Air Limbah yang digunakan adalah Anaerobic Baffled Reactor dan Anaerobic Filter. Pembangunan dilakukan dengan 3 tahapan yaitu tahun 2017, tahun 2026, dan tahun 2036.

D. Biaya yang dibutuhkan dalam pembangunan SPAL dan IPAL Kelurahan Kedung Cowek adalah sebesar Rp2.942.828.173,- Dengan biaya retribusi sebesar Rp $10.000,00 /$ KK.bulan untuk perawatan dan pengoperasian.

\section{SARAN}

Beberapa saran yang diberikan dari perencanaan ini adalah:

A. Biaya retribusi oleh masyarakat diharuskan tetap sama setiap bulannya yaitu sebesar Rp 5.000,00 10.000,00/KK.bulan, hal ini demi menjaga persepsi masyarakat bahwa mewujudkan kehidupan sehat itu tidak terlalu mahal. Stabilitas retribusi bisa dilakukan dengan cara pemberian subsidi oleh Pemerintah Kota Surabaya.

B. Perlu adanya kerjasama antara UPT dengan kader lingkungan yang sudah dibentuk. Koordinasi ini bertujuan untuk memudahkan pengoperasian dan perawatan SPAL dan IPAL Komunal di Kelurahan Kedung Cowek. Selain bertanggung jawab terhadap pengoperasian SPAL dan IPAL Komunal, UPT atau kader lingkungan diharapkan bisa menjadi sosok yang mampu mengajak masyarakat berperilaku sanitasi sehat terutama pada sektor air limbah.

C. Perlu adanya sosialisasi dan penyuluhan kesehatan untuk semua warga Kelurahan Kedung Cowek. Sosialisasi dan penyuluhan diprioritaskan pada warga RW I, di mana sebagian besar warganya menolak keberadaan SPAL dan IPAL Komunal. Sosialisasi dan penyuluhan bisa menjadi mediasi agar masyarakat sadar akan hidup sehat dan mau berpartisipasi dalam SPAL dan IPAL Komunal Kelurahan Kedung Cowek.

\section{DAFTAR PUSTAKA}

[1] Afandi, Y. V., Sunoko, H. R., Kismartini. 2013. Status Keberlanjutan Sistem Pengelolaan Air Limbah Domestik komunal Berbasis Masyarakat. Jurnal Ilmu Lingkungan, Vol. 11, Issue 2: 100-109.

[2] Suprijanto, Iwan. 2001. Karakteristik spesifik, permasalahan \& potensi pengembangan kawasan kota tepi laut/pantai (coastal city) di Indonesia. Proceeding Studi Dampak Timbal Balik Antar Pembangunan Kota \& Perumahan di Indonesia dan Lingkungan Global. Pusat Penelitian dan Pengembangan Permukiman.

[3] Haryandi. 2007. Pemberdayaan Masyarakat Terhadap Pengelolaan Lahan Wilayah Pesisir di Pantai Timur kabupaten Lampung Selatan.

[4] Wiyana, Adi. 2004. Faktor Berpengaruh Terhadap Keberlanjutan Pengelolaan Pesisir Terpadu (P2T).

[5] Sasse. 2008. DEWATS: Decentralized Wastewater Treatment In Developing Countries. Bremen: BORDA

[6] Metcalf \& Eddy, Inc. 2004. Wastewater Engineering: Treatment and Resource Recovery, Fifth Edition (International Edition). Singapore: McGraw-Hill Company, Inc.

[7] http://www.bi.go.id/en/moneter/inflasi/data/Default.aspx (diakses pada 16 Juni 2016). 